\title{
Doodle: an innovative tool for organizing group tutorials in University education
}

\author{
Paula Bastida-Molina ${ }^{a}$, Carlos Vargas-Salgado ${ }^{b}$, Lina Montuori ${ }^{c}$, Manuel Alcázar- \\ Ortega $^{d}$ \\ a Instituto Universitario de Investigación en Ingeniería Energética, Universitat Politècnica de \\ València, Camino de Vera, s/n, edificio 8E, acceso F, 2 $2^{\mathrm{a}}$ planta. 46022 Valencia (España), \\ paubasmo@etsid.upv.es, ${ }^{b}$ Departamento de Ingeniería Eléctrica, Universitat Politècnica de València, \\ Camino de Vera, s/n, edificio 5E, planta baja. 46022 Valencia (España), carvarsa@upvnet.upv.es, \\ ${ }^{\mathrm{c}}$ Departamento de Termodinámica Aplicada, Universitat Politècnica de València, Camino de Vera, \\ s/n, edificio 5J, $2^{\mathrm{a}}$ planta. 46022 Valencia (España), lmontuori@upvnet.upv.es, ${ }^{\mathrm{d}}$ Departamento de \\ Ingeniería Eléctrica, Universitat Politècnica de València, Camino de Vera, $\mathrm{s} / \mathrm{n}$, edificio $5 \mathrm{E}, 2^{\mathrm{a}}$ planta. \\ 46022 Valencia (España), malcazar@iie.upv.es
}

\begin{abstract}
Group tutorials are becoming an ever-increasing learning methodology in University education due to the continuous knowledge feedback among students. Despite the positive impact of such kind of sessions on students, their previous organization phase remains most of the times misleading. The traditional way of arranging a group tutorial through e-mail normally results in a long and ineffective method mainly caused by the different schedule availability between the professor and the different students. Is in this context where Doodle arises as a virtual application to enhance this first group tutorial phase. Generally, Doodle allows users to schedule meetings in a quick, effective and free way: the organizer creates a new meeting, proposes different schedule options and invites the other participants through an email invitation or a link created by Doodle. Then, participants vote for the schedule options that best fit their availability, so that the final meeting schedule is selected democratically. In the University context, professors would play the role of organizers and students of participants, respectively. In this paper, we analyze the application of Doodle in the organization of a group tutorial of students of Electrical Circuits from the Bachelor Degree in Electrical Engineering (Polytechnic University of Valencia). Particularly, the tutorial was formed by six students and the professor, and took place in the Department of Electrical Engineering. After the meeting, the students answered a survey. Their answers reveled the positive acceptance of Doodle among them in terms of efficiency and ease of use. 100\% of them agree on its
\end{abstract}


suitability for arranging future group tutorials. Moreover, a comparative study demonstrated that using Doodle instead of e-mail while arranging a group tutorial leads to an average of up to $64 \%$ reduction in process time.

Keywords: Doodle, group tutorials, knowledge feedback, innovation in organization.

\section{Introduction}

University education is experimenting a profound evolution enhanced by the development of new learning methods, the introduction of digital tools and the change of the traditional roles professor-students (Baelo \& Cantón, 2009; De Pablos Pons, 2007). Concerning the last concept, modern university education considers the student and the professor two complementary parts of the learning process, where each of them can learn from the other one (Harden \& Crosby, 2000). Moreover, modern education also understands the necessity of identifying the specific necessities of each student, beating for a more self-personalized education (De Miguel Díaz, 2005; Ginés Mora, 2004). Thus, group tutorials emerge as a great educational method, since professors can focus on the difficulties of a reduced group of students, whereas the latter could also benefit from a continuous feedback studentstudent and student-professor (Dolmans \& Schmidt, 2006).

Despite the benefits of group tutorial for higher educational levels, their previous schedule stage results complicated, slow and inefficient most of the times. The traditional method used, the e-mail, allows for a bidirectional communication but not for a multidirectional one. This feature emerges as a problem in group tutorials, since more than two people are involved in the process, normally with different schedule availabilities (Grandgenett, 2008).

To cope with the difficulties associated to the schedule of group tutorials using traditional methods, we propose the introduction of a new virtual tool in such process: Doodle. It is a free platform that allows all the participants taking part in the meeting to digitally vote the schedule alternative that best fits their availability, without the necessity of being simultaneously connected to the platform (Zou, Meir, \& Parkes, 2015).

It has been widely used in the organization of business, scientific or even professors' meetings, resulting an extremely efficiency tool (Reinecke, Nguyen, Bernstein, Näf, \& Gajos, 2013). In spite of its positive outcomes in such working fields, its use for educational purposes remains unexplored. Therefore, we have applied it to a specific educational case of study. Particularly, in this paper we have applied Doodle to the arrangement of group tutorials in the course Electrical Circuits, which corresponds to the 
first course of the Bachelor Degree in Electrical Engineering, at the Polytechnic University of Valencia.

This paper is structured as follows. Section 2 describes the educational methodology here presented. Section 3 shows the results and discussion of applying such method to the Electrical Circuits course. Finally, section 4 reflects the main conclusions extracted from this work.

\section{Educational Methodology}

In this section, we describe the educational methodology followed to schedule group tutorials using Doodle in the course Electrical Circuits, which corresponds to the first course of the Bachelor Degree in Electrical Engineering, at the Polytechnic University of Valencia (Polytechnic University of Valencia, 2019a). The methodology is hereby presented:

- Firstly, the professor detects the necessity of establishing a group tutorial with the students, normally motivated by the amount of questions arose amongst them regarding a specific topic or the level of difficulty of such topic. He/she also identifies the students that are interesting in attending the group tutorial.

- Then, the professor starts the process of arranging the group tutorial using Doodle. With this platform, he/she creates a new meeting, acting therefore as organizer. The professor also proposes different schedule options for the group tutorial, always considering the official university schedule of the students, available on (Polytechnic University of Valencia, 2019b). He/she also defines the place where the tutorial will take place, being sure of its availability at the proposed times.

- Once all the options are set up, Doodle generates a link to access to the meeting arrangement. The professor sends this link to all the students willing to take part in the group tutorial, so that they acquire the role of participants.

- Finally, the students vote for the schedule options that best fit their availability. Doodle registers their votes, so that the most voted alternative results to be the chosen one to arrange the group tutorial. The professor also informs about this final decision. 


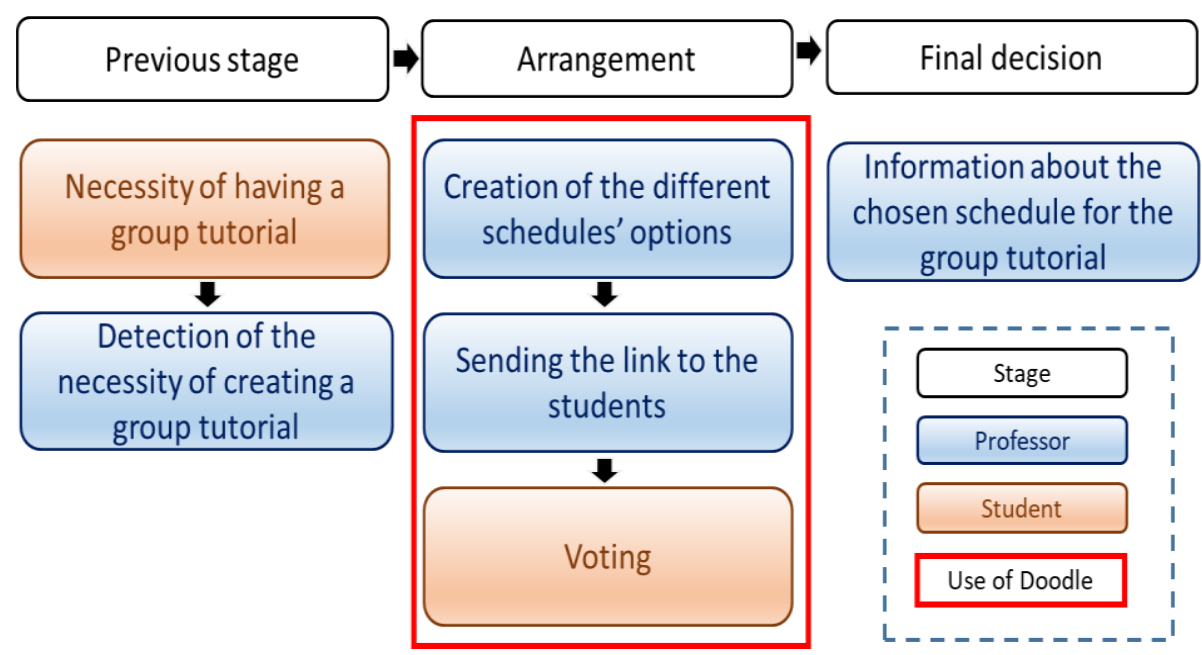

Fig. 1. Flowchart of the educational methodology.

\subsection{Efficiency assessment of the methodology}

To prove the efficiency degree of using Doodle to arrange group tutorials in Electrical Circuits, we made a comparison between this new method and the traditional e-mail system. Specifically, we compared the time that was needed to arrange the group tutorial by Doodle with the time that was needed to do so by e-mail. To make a suitable comparison, the tutorials were equivalents in terms of number of students.

\subsection{Students' opinion}

Due to the innovative character of such methodology, we considered that having the feedback of students after having arranged a group tutorial through Doodle would be of great value to analyse its suitability (Harden \& Crosby, 2000). Hence, we prepared the following questionnaire to be answered by them, being 5 the highest level of agreement and 1 the lowest: 
Table 1. Questionnaire to know student's opinion.

\begin{tabular}{|c|c|}
\hline Questions & Possible answers \\
\hline Q1. Did you know the tool Doodle? & Yes / No \\
\hline Q2. Have you previously used it to arrange a group tutorial? & Yes / No \\
\hline $\begin{array}{l}\text { Q3. To which extend was it easy for you to use Doodle to arrange } \\
\text { the group tutorial? }\end{array}$ & $5 / 4 / 3 / 2 / 1$ \\
\hline $\begin{array}{l}\text { Q4. To which extend do you consider is Doodle an effective tool to } \\
\text { arrange a group tutorial? }\end{array}$ & $5 / 4 / 3 / 2 / 1$ \\
\hline $\begin{array}{l}\text { Q5. To which extend do you prefer Doodle to arrange future group } \\
\text { tutorials rather than any other traditional methods, such as e-mail? }\end{array}$ & $5 / 4 / 3 / 2 / 1$ \\
\hline
\end{tabular}

\section{Results and discussion}

In this section, we present the results obtained from the application of the proposed methodology to a specific group tutorial of the course Electrical Circuits. Particularly, the group was formed by six students who had doubts about some aspects of the practice lessons. The tutorial took place in the Department of Electrical Engineering.

\subsection{Efficiency assessment of the methodology}

The group tutorial organized by Doodle was compared with an equivalent group tutorial arranged by e-mail. Results reveal that the e-mail tutorial needed 100 hours and 18 e-mails to be arranged, whereas the Doodle tutorial only required $36 \mathrm{~h}$ and 3 e-mails. Hence, a decrease of $64 \%$ and $83 \%$ of time and number of e-mails, respectively, has been achieved with the introduction of the new methodology.

\subsection{Students' opinion}

After the group tutorial, all the students agreed to answer the questionnaire described in section 2.2. Fig. 2, Fig. 3 and Fig. 4 reflect their opinion about the introduction of the educational method. 
Firstly, Fig. 2 shows us that, although approximately half of the students knew what was Doodle (Fig. 2 (a)), none of them had previously used in the arrangement of a group tutorial (Fig. 2 (b))). Such outcome highlights the innovative character of the methodology proposed in this paper.

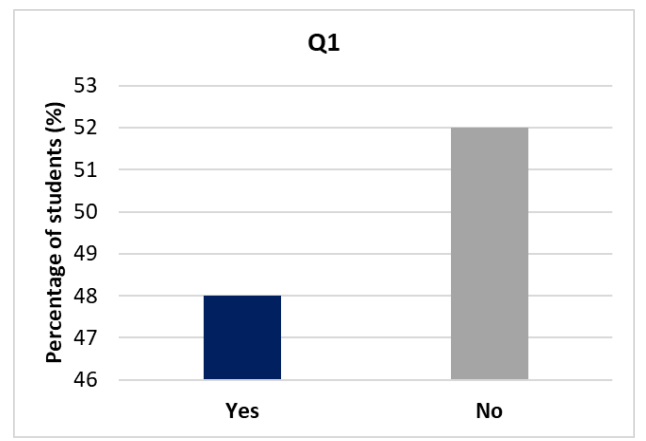

(a)

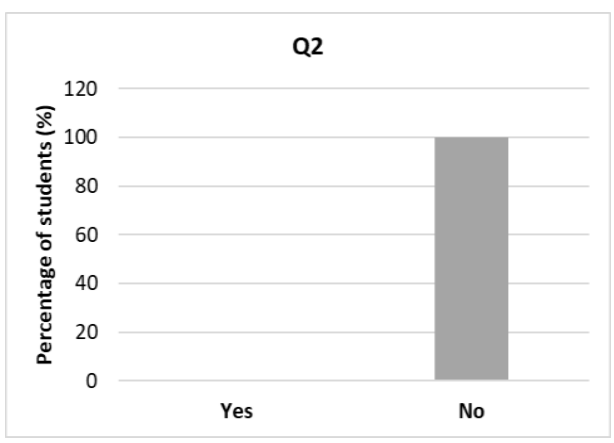

(b)

Fig. 2. Students' opinion. (a) Q1. (b) Q2.

Moreover, the opinion of the students reflected in Fig. 3 reveals the ease of use of Doodle: $79 \%$ and $17 \%$ of the students completely or almost completely agree about its ease of use, respectively.

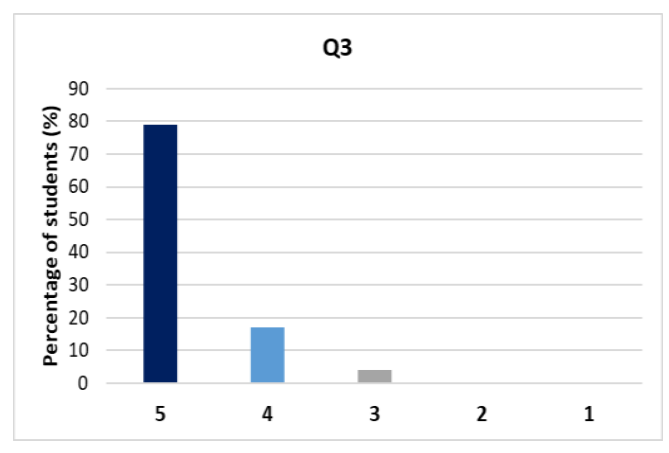

(c)

Fig. 3. Students' opinion. (c) Q3. 
Finally, Fig. 4 indicates that almost all the students (84\%) considered to the widest extend that Doodle was a really effective tool to arrange group tutorials (Fig. 4 (a)), whereas all of them $(100 \%)$ said that they would completely prefer using Doodle to arrange future group tutorials rather than using traditional methods, such as e-mail (Fig. 4 (b)).

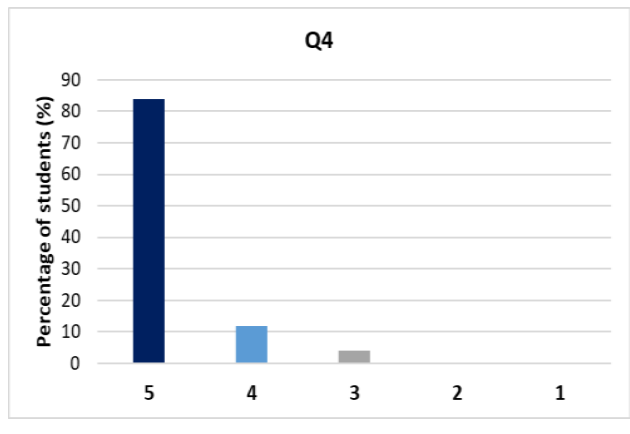

(d)

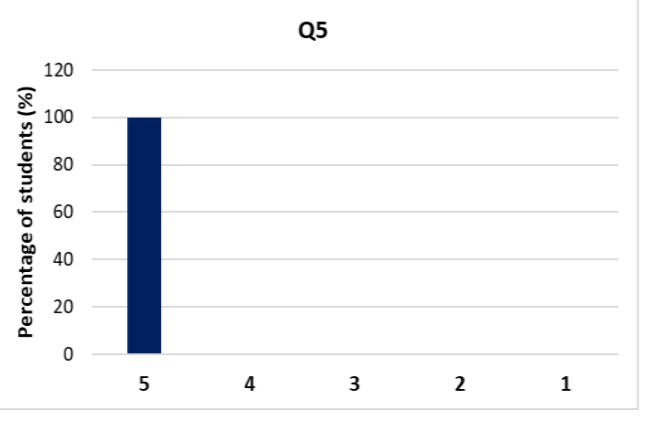

(e)

Fig. 4. Students' opinion. (d) Q4. (e) Q5.

\section{Conclusions}

University education is suffering a deep change, based on the development of new learning methods, the introduction of digital tools and the change of the traditional roles professorstudents. Hence, new education, unlike traditional one, focuses the attention on the students and bets for a more self-personalized education. In line with this last concept, modern university education considers the group tutorials essential for two main reasons. On the one hand, the reduced number of students having the tutorial allows the professor to pay special attention to the individual necessities of each student. On the other hand, the interrelationship among students and professors gives raise to continuous knowledge feedback.

Despite the suitability of such kind of tutorials, its previous schedule phase results most of the times complicated, mainly due to the high number of people involved and their different schedule availabilities.

In this paper, we have proposed the introduction of a new virtual tool called Doodle to cope with the difficulties associated to the schedule of group tutorials. When professors detect the necessity of creating a group tutorial, Doodle allows them to propose different schedule 
options for it and send them to the students willing to take part in the tutorial through a link. Therefore, students just have to vote for the options that best fit their availability, so that the schedule of the tutorials is selected democratically. Moreover, Doodle is free and neither the organizer nor the participants need to register to use it.

Particularly, we have applied this new methodology to the arrangement of group tutorials in the course Electrical Circuits, which corresponds to the first course of the Bachelor Degree in Electrical Engineering, at the Polytechnic University of Valencia.

After arranging a particular group tutorial using this methodology, a comparative study between that tutorial and an equivalent one organized by a traditional method (e-mail) were compared. Results revealed that a reduction of $64 \%$ and $83 \%$ of time and number of emails, respectively, was achieved.

Besides, the students who took part in the analysed tutorial were asked to answer a quick questionnaire to know their opinion about the new virtual tool. Approximately, half of the students surveyed knew what was Doodle, but none of them had previously use it in the schedule process of a group tutorial. Despite this, $79 \%$ found the application completely easy to use. Finally, $84 \%$ of the students considered Doodle a total effective tool to arrange group tutorials, and all of them expressed their preference of using Doodle rather than other traditional methods, like e-mail, to schedule future group tutorials.

Hence, this paper reflects the application of Doodle to arrange a specific group tutorial of six students from the Electrical Circuits course. This methodology was also used to organize a wide range of group tutorials in such course, all of them between three and ten students. However, authors decided to analyse the specific case study of six students to compare it with an equivalent group tutorial arranged by e-mail. Moreover, six was the average number of members that formed the group tutorials.

With the results obtained, we have proved the effectivity of introducing Doodle while scheduling group tutorials, along with its acceptance among students.

\section{Acknowledgments}

This work was supported in part by the regional public administration of Valencia under the grant ACIF/2018/106.

\section{References}

Baelo, R., \& Cantón, I. (2009). Las tecnologías de la información y la comunicación en la educación superior. Estudio descriptivo y de revisión. Revista Iberoamericana de Educación, 50(7), 1-12. 
De Miguel Díaz, M. (2005). Cambio de paradigma metodológico en la Educación Superior Exigencias que conlleva. Cuadernos de Integración Europea, 16-27.

De Pablos Pons, J. (2007). El cambio metodológico en el Espacio Europeo de Educación Superior y el papel de las tecnologías de la información y la comunicación. RIED: Revista Iberoamericana de Educación a Distancia, 10 (2), 15-44.

Dolmans, D. H. J. M., \& Schmidt, H. G. (2006, November 5). What do we know about cognitive and motivational effects of small group tutorials in problem-based learning? Advances in Health Sciences Education. Springer. https://doi.org/10.1007/s10459-006-9012-8

Ginés Mora, J. (2004). La necesidad del cambio educativo para la sociedad del conocimiento. Revista Iberoamericana de La Educación, 35, 13-37.

Grandgenett, N. (2008). DOODLE. Mathematics and Computer Education.

Harden, R., \& Crosby, J. (2000). The good teacher is more than a lecturer - the twelve roles of the teacher. Medical Teacher, 22, 334-347.

Polytechnic University of Valencia. (2019a). Electrical Circuits. Retrieved June 13, 2020, from https://www.upv.es/titulaciones/GIEL/menu_1014686c.html

Polytechnic University of Valencia. (2019b). Schedules GIE $1^{\circ}$ 2019/2020. Retrieved June 13, 2020, from http://www.etsid.upv.es/horarios-gie-1o-2019-2020/

Reinecke, K., Nguyen, M. K., Bernstein, A., Näf, M., \& Gajos, K. Z. (2013). Doodle around the world: Online scheduling behavior reflects cultural differences in time perception and group decision-making. In Proceedings of the ACM Conference on Computer Supported Cooperative Work, CSCW (pp. 45-54). New York, New York, USA: ACM Press. https://doi.org/10.1145/2441776.2441784

Zou, J., Meir, R., \& Parkes, D. C. (2015). Strategic voting behavior in doodle polls. In CSCW 2015 Proceedings of the 2015 ACM International Conference on Computer-Supported Cooperative Work and Social Computing (pp. 464-472). New York, New York, USA: Association for Computing Machinery, Inc. https://doi.org/10.1145/2675133.267527 